\title{
Oral history and the epistemology of testimony
}

\section{Introduction}

The epistemology of testimony is concerned with the conditions, if any, under which testimony leads to justified beliefs and knowledge. It is not the only field to have this concern, though. Pitched at this level of description, other fields of study too have a significant interest in testimonial justification and knowledge: jurisprudence, to take just one example. A natural thought is that social epistemologists would do well to pay close attention to what experts in these other fields say about testimony.

Philosophers have done a little of this, but not a lot. There have been epistemological treatments of expert testimony as found in law (Walton 2008), in science (Almassi 2009a, 2009b), and in both law and science (Miller forthcoming). But we can put a finer point on the issue by noting that, for reasons I will touch upon below, epistemologists of testimony have focused disproportionately on the epistemological character and implications of oral testimony. The philosophical literature has had very little to say about other disciplines' principles or methods bearing specifically on the credibility or the justified acceptance of oral testimony, however. Epistemologists have preferred to use highly simplified fictional examples in discussing oral testimony, rather than seeking examples or case studies from fields having a focus on it. In particular, social epistemology in the analytic tradition has found very little to say about the field of oral history as a source of insight and examples. 
Historians with a methodological focus on orality presumably have an expert perspective on the credibility of such testimony. Their interest and their expertise, whatever else it encompasses, is apt to include a focus on both recognizing and engendering circumstances in which oral testimony is truth-conducive, conferring justified beliefs about past events on its audience. ${ }^{1}$ So it is prima facie reasonable to expect that oral historiographers' principles and practices should illuminate social epistemology's own inquiries into the basic acceptability conditions and epistemic functions of testimony, while providing a stock of real-world examples for analysis. So why haven't philosophers mined oral history for testimonial insights and examples? Not because they are somehow opposed to the idea, of course. There are fair explanations for caution about this sort of mining: working within a discipline is perfectly legitimate scholarship in itself; synthesizing the work of distinct disciplines is both difficult and time-consuming; and it is easy to misuse or misconstrue research done in fields on which one is not an expert.

I hope it is not simply a measure of my lack of scruple on this last front that I will, in the following remarks, propose some lessons that the methods and presuppositions of oral historiography hold for the epistemology of testimony. No doubt there are many such lessons, but I will divide my focus between one negative lesson and a collection of positive ones suggested by a reading of some seminal work in the historiography of oral

\footnotetext{
${ }^{1}$ This is plausible of oral historiographers as a group, though not necessarily as individuals; a methodologist may well not have much specific focus on truth-conducivity tout court. The plurality of methods and objectives of oral historians is worth noting. For current purposes, however, it is sufficient to focus on the relevance to epistemology of those oral historiographers who are, in fact, concerned with the conditions under which testimony licenses knowledge or justified belief about history, broadly conceived. I return to this question briefly in section 5.4 below.
} 
traditions. The negative lesson arises from an idea advanced by C.A.J. Coady (1992): that expert oral historians treat testimony with a default trust, and that this suggests a standing epistemic warrant for the acceptance of testimony even when independent supporting evidence is unavailable. This idea is not supported by the reflective views on oral historiography expressed by some influential writers in the field (including those cited in its favor). So I reject it. Rather, oral history and its methods are valuable for directing our attention to underemphasized aspects of testimonial contexts and the uses of testimony.

This is where the positive lessons come in. Oral history, in the broadest sense, highlights the extent to which the epistemic value of testimony is a function of the ways in which testimonial contexts are actively constructed by speakers, audiences, institutions and whole societies. It also indicates the epistemological importance of social, cognitive and epistemic properties of the audience, when much philosophical focus has typically been on properties of the testifier. And it introduces a wider range of respects in which testimony is truth-conducive than the fairly limited sense generally emphasized in the philosophical literature. These lessons are of course defeasible; they are drawn from a partial survey of a large interdisciplinary literature, and apply only to some extent or other. But they hold out the promise of a broader and more empirically informed approach to testimony. The epistemology of testimony currently suffers from a degree of oversimplification; oral history, I argue, is one important source of relevant salutary complications.

2. Why oral testimony? 
Testimony can be verbal, written, or signed. So why the focus on orality? ${ }^{2}$ Social epistemologists have converged on the use of (seemingly) simple examples of oral testimony, and especially oral testimony from strangers, as illustrations and even as data points for their reasoning about testimony. Commonly cited cases include testimony elicited by asking strangers for directions, or for the time of day, or for mundane information like their birthdays, telephone numbers, or what they had for breakfast. The phenomenon of interest is the immediate uptake and acceptance of this sort of oral testimony - the automatic, fast and implicit process that I have elsewhere called the default acceptance of testimony (ELIDED).

This focus arises in part from philosophical debates about the justification of beliefs formed from testimony. One much-discussed family of views depicts the justification for these beliefs as resting on, continuous with, or otherwise inextricable from evidence of fairly general sorts: inductive evidence over a range of domains, theoretical knowledge of various kinds, and intermingled demonstrative and nondemonstrative inference. This approach is often termed reductionism. In its most extreme empiricist or atomist form, it would reduce the justification for all testimonial belief to a complicated skein of testimony-independent information based on perception, memory, and reason. More moderate versions do not require global reduction to non-testimonial evidence, holding rather that a particular instance of testimony is rationally credible only

${ }^{2}$ In what follows, I follow the epistemology literature in focusing on oral communication as the contrast case to written communication. However, I conjecture that the ephemerality of the signal and the immediacy of uptake characteristic of sign language means that substantially similar remarks should apply to signed testimony as apply to oral testimony. It is nevertheless worth flagging the possibility that characteristics of sign language raise distinct questions of testimonial epistemology. For current purposes I will simply rely on the term 'audience' as less presuppositional of oral communication than the more common term 'hearer'. 
to the extent that it is supported by evidence independent of the particular testimony

itself. ${ }^{3}$

On a competing approach, by contrast, there is a default warrant or epistemic right to believe testimony - a presumptive sui generis license that may be overridden by other evidential considerations, but which does not itself resolve into other evidential considerations. The mere fact that someone has asserted a proposition (or, alternatively, the audience's recognition of this fact) is prima facie sufficient justification for believing what has been asserted, in the absence of evidential considerations that defeat this justification. ${ }^{4}$ This view is sometimes termed credulism or fundamentalism; really, it's the view that the justifying properties of testimony are special to it. Tyler Burge frames this view as the Acceptance Principle for Testimony (APT), crediting Thomas Reid for the insight.

(APT): A person is entitled to accept as true something that is presented as true and that is intelligible to him, unless there are stronger reasons not to do so (Burge 1993, p. 467).

\footnotetext{
${ }^{3}$ This latter point suggests that 'reductionism' and 'reductivism' are misleading terms for the class of positions taken to fall under them. The idea most widely shared among the class is not to eliminate or reinterpret testimonial justification in terms of some underlying reductive type or discourse, but rather to draw out the dependence relations between the epistemic improvements conferred on an audience by an instance of testimony, and other evidence or information available to the audience. I take this to be a key lesson of Karyn Freedman's Dependence Account of testimonial justification (2014). For current purposes, however, I will stick with the dubious but familiar terminology.

${ }^{4}$ Though reductionism may be associated with both internalism and inferentialism, and fundamentalism with externalism and noninferentialism, this association is best regarded as loose and contingent. The parenthetical variant included here, invoking the importance of the believer's recognizing that an assertion has been made, would signal an internalism-friendly version of fundamentalism.
} 
APT is not quite the view that testimonial justification isn't evidential or informationbased. Certainly it takes seriously that the relevant entitlement requires the absence of evidential defeaters ("stronger reasons") in the audience's set of beliefs. But it does propose at least that a special and quite limited evidential datum - roughly, that a proposition has been asserted and understood - is sufficient for the justified acceptance of testimony, other things being equal.

This backdrop of debate over whether the justification of testimony is evidentially complicated or evidentially special helps explain the focus on oral testimony. ${ }^{5}$ If we considered cases in which the audience took plenty of time in evaluating the credibility of a piece of testimony, and carefully pondered lots of supporting evidence about it, we might end up conflating the potentially purest case of testimonial justification with all kinds of other, more general, evidential considerations. The automatic, fast and implicit uptake associated with default acceptance, by contrast, seems likeliest to factor out these potential complications, and reveal a sui generis justification for accepting testimony if there is one. After all, virtually everyone agrees that a belief arising from testimony can be justified when the believer possesses and uses independent evidence that supports it. That sort of evidence may well be significant in cases of prolonged reflection, or when the testimony bears on matters that are supported by non-testimonial evidence within the context of uptake. Hence those cases are not suited to distinguish reductionist from

\footnotetext{
${ }^{5}$ In explaining why oral testimony is of particular significance to this literature, I am simplifying a complex terrain of positions. The two families of positions summarized here are interpolated and complicated by other positions - for example, those of Jennifer Lackey (2008) and Peter Graham (2006) - that may not fall neatly into either camp.
} 
fundamentalist assessments of the justificatory status of such beliefs. By contrast, oral testimony in low-information default acceptance contexts, in which the audience possesses or deploys little evidence about the speaker's record of reliability, or the facts on which the testimony bears, seems more apt to reveal minimally sufficient acceptability conditions for testimony.

In short, oral testimony by people about whom little is known, yet which receives rapid and unreflective uptake, might provide cases that aren't cluttered with a lot of relevant evidence additional to a putative justificatory minimum for testimonial acceptability. A focus on verbal testimony in low-information contexts is apt to reveal whether there at least some cases of intuitively justified testimonial beliefs that could be explained if the justification were fundamentalist, but not if it were reductionist. These would be cases of intuitively justified testimonial acceptance, yet with clearly insufficient contextual supportive evidence for the proposition asserted.

\section{APT and the reliability of oral history over repeated transmissions}

One way for oral history to be relevant to the epistemology of testimony would be if it offered support for something like APT. One might conclude that it does offer such support, if it turned out that historians with expertise in the evaluation of oral testimony actually adopted an attitude of default acceptance towards oral testimony - that is, if they did so even in low-information contexts lacking independent evidence sufficient to bear out the proposition asserted, or sufficient to evidentially establish the personal credibility of the speaker. That oral reports of this kind are treated as default-reliable by historians is 
suggested by C.A.J. Coady, as part of his broader case that testimony is more readily trustworthy than at least one sort of reductionist account of testimonial acceptability would have it. Coady argues for a standing justification to accept testimony, roughly analogous to the warrant that perception provides for perceptual beliefs (1992, p. 145).

There is a pretheoretic appeal to this suggestion in the case of oral traditions. These are oral histories in which testimony is handed down over generations - even, in theory, from the distant past. In these cases the content of the testimony may purport to bear on remote events that have left no clear traces of supporting evidence. If such testimony were rationally acceptable by default, then there would be reason to think that its justified uptake is inherent to testimony itself. It would suggest that some sort of justification is transmitted, without diminishment, by testimony across generations and over many re-tellings, something that is not dependent on ancillary supporting information attending on each instance of transmission. ${ }^{6}$ If oral historians generally accepted such testimony, and in particular if they accepted by default in low-information contexts, for reasons recoverable in terms of their commonly accepted disciplinary methodology, this would bolster APT by showing that it is used or assumed by these experts on testimonial credibility.

Coady, to his great credit, is one of very few epistemologists of testimony to have taken seriously the relevance of historiography. His defense of the credibility of

\footnotetext{
${ }^{6}$ The distinction between oral history, meaning oral testimony from a purported direct witness to historical events, and oral traditional history, meaning a testimonial tradition handed down over generations, is implicit in much of the historiography literature, but is made explicit in some of it (Dunaway and Baum 1984, p. 165). The expression 'oral testimony' is sometimes associated with formalized contexts, including legal hearings, in the history literature; here I am adopting the less formal use this expression would receive in the epistemology literature, to denote oral reports simpliciter.
} 
specifically oral traditions is one point in his cumulative case against what he calls "the disappearance of history thesis" (1992, p. 199). This thesis, to which Coady believes broadly reductionist approaches to testimony lend themselves, is that the credibility of testimony about past events must diminish as that testimony is transmitted from speaker to speaker over many years. John Locke courts this view in the Essay, where he writes that, for any testimony,

the further off it is from the original truth, the less force and proof it has. The being and existence of the thing itself, is what I call the original truth. A credible man vouching his knowledge of it is a good proof; but if another equally credible do witness it from his report, the testimony is weaker: and a third that attests the hearsay of an hearsay is yet less considerable (Bk IV, ch xvi, s.10).

In fact Coady takes Locke as his main philosophical opponent on the matter of historical testimony, focusing on Locke's broadly probabilistic argument for the diminution of credibility over repeated transmissions.

$[\mathrm{N}]$ o probability can rise higher than its first original. What has no other evidence than the single testimony of one only witness must stand or fall by his only testimony, whether good, bad, or indifferent; and though cited afterwards by hundreds of others, one after another, is so far from receiving 
any strength thereby, that it is only the weaker... [A] thousand odd reasons, or capricios, men's minds are acted by, (impossible to be discovered,) may make one man quote another man's words or meaning wrong (Essay, bk IV, ch xvi, s.11). ${ }^{7}$

Nor need we look as far into the past as Locke to see this line of reasoning defended. The argument is more recently echoed, with some refinements, by historiographer David Henige:

The load-bearing capacity of an argument based on a string of unconfirmed sources is dangerously modest. The probability that such an argument is correct founders on the axiom that probabilities multiplied are probabilities diminished. Since no single testimony can have a probability of 1.0, each time these are associated with (i.e., multiplied by) another one, the overall argument is increasing in danger. Even three sources that the historian deems 75 percent correct amount, when used in concatenation, to a probability of $.75^{3}$ or about 4 in 10 . Reduce the individual probabilities to 60 percent and the result is barely 20 percent $(2005$, p. 55).

\footnotetext{
${ }^{7}$ This does raise questions about the empirical assumptions underlying Locke's accompanying claim, in the same chapter, that "if all historians that write of Tiberius, say that Tiberius did so, it is extremely probable" (Essay, bk IV, ch xvi, s.7.III). Presumably this means either that Locke's historians are not working "one after another" within a single tradition over time, or that they have some special evaluative powers that greatly mitigate the prospects of error.
} 
Both Locke and Henige are careful to flag two key assumptions of this sceptical argument, though: namely, that no other evidence is implicated, and that the testimonial transmission occurs in a strict series. Coady rightly observes that these assumptions may well fail to hold (p. 215). Lingering traces of independent evidence can bear on the content of the testimony even as it is transmitted; and distinct versions and transmissionchains of the testimony may be causally entangled in a community, each capable of acting as a check on changes in the content of the others. These persisting evidential traces and social interaction effects confound the rather simplistic assumption of independent probabilities in the Locke-Henige argument.

This is a persuasive response, but not one that offers much comfort to the friend of APT. It shows that the credibility of testimony may degrade more slowly than the Locke-Henige argument suggests. But it explains this by appeal to the persistence of independent evidence and overlapping chains of testimonial transmission. Justified testimonial acceptance under those conditions does not bear out APT; rather, these look like the "evidential clutter" cases described earlier. That is, they feature independent lines of evidence bearing some of the justificatory burden for beliefs arising from the testimony. By contrast, APT implies that as the available independent supporting evidence thins out to nothing, as the number of testimonial transmissions increases with the passage of time, the justification for accepting the testimony (in the absence of defeating conditions) should reach a floor below which its rational credibility does not sink. This floor level, moreover, should be great enough to license accepting the testimony - again, provided that no positively countervailing evidential considerations 
undermine that justification. In other words, the degradation of credibility over repeated transmissions of testimony should be trumped by something discrete and non-diminishing in the testimony itself. This special something, according to APT, is the standing warrant to accept testimony simply on the grounds that it has been asserted.

So the reply from persisting independent evidence may force complications upon the probabilistic diminishing-credibility argument; by itself it's not a reply that bolsters the APT perspective. The key question is whether oral historians really do treat oral traditions as default-credible when independent support for the propositions they express is not available. And the answer to this key question is: no, they don't. Or, allowing for the complexity and heterogeneity of a sprawling literature and overlapping disciplines: no, they mostly don't.

4. What oral history does not show about the epistemology of testimony

Some writers do take testimonial credulity to remarkable lengths in the absence of specific information about the intervening contexts of transmission. Henige cites examples of authors willing to accept the reliability of oral traditions extending 1200 , 10000,13000 , and even 40000 years into the past (2005, pp. 88-9). ${ }^{8}$ One of these writers considers the prospects to be (merely!) "not implausible", while others advertise "clinching evidence," or that "there can be little doubt" about the tautness of the testimonial chain over millennia. In principle, claims like these could be advanced by specialist historians - that is, by researchers self-identifying, and identified by their

\footnotetext{
${ }^{8}$ See also Deur (2002), who posits a testimonial chain surviving 8000 years while preserving accurate details of the formation of Oregon's Crater Lake among the nearby indigenous Klamath people.
} 
discipline, as experts in oral history or historiography first and foremost. But Henige's specific examples of writers claiming the preservation of accurate oral testimony from the remote past turn out to involve two linguists, two geographers, a historian not based in a university, and an anthropologist. Without dwelling on the fraught territoriality that can arise in the individuation of disciplines and sub-disciplines, we may note that one partial explanation for such claims might be a lack of immersion in the methods that inform oral history as practiced by historians. ${ }^{9}$

Yet even professional academic historians who do not endorse specific claims about accurate oral traditions from the remote past may yet postulate reliable mechanisms of content-preservation in the oral transmission process. Reliable mechanisms of belief formation and content-preservation more generally are of great interest to epistemologists. If we can postulate reliable belief formation in the first instance, then contentpreservation over testimonial transmission should mean that testimony is reliably truthconducive - perhaps even in the context of longer-term oral traditions. This is precisely the theme that Coady develops, noting that "there are ways in which the reliability of the witnesses in the chain can be made very high indeed" in the transmission of oral histories.

\footnotetext{
${ }^{9}$ Some defenses of the long-term fidelity of oral traditions may be generally methodologically incautious, but others may simply assume that the proofs of this fidelity are already a matter of record. Sitton, Mehaffy and Davis write that other researchers "have documented the orally communicated history of many non-Western societies around the world and in the process have produced powerful evidence for the potential value of human memory as historical evidence" $(1983, \mathrm{p}$. 8). They cite a passage from Allen and Montell (1981), who assert that orally communicated histories have "a marked propensity for retaining historical truths over long periods of time," but who in turn appeal chiefly to remarks in Liestøl's work on Icelandic epics (1930), and to the genealogical evidence claimed (at one time) by Roots author Alex Haley, as evidence for their defense of multi-generational traditions specifically. The ultimate evidential grounding for this chain of claims is more modest than the confidence placed in its final link. More recent methodology by turns qualifies and supports such claims in terms of the cognitive and neurological bases of memory (Yow 2005; Thomson 2011).
} 
Much oral tradition in societies without writing is strongly

institutionalized so that specially selected people are given the privilege

and onerous duty of being the custodians of the society's past. The

histories are often in the form of songs or poems and they are learnt off by

heart by specialists from specialists. In some societies, there are not only

privileges for such people but heavy ritual sanctions against mistake (p.

216).

A broadly reliabilist or otherwise externalist story of the justified default uptake of oral history glimmers in these remarks: the system of testimonial transmission is policed for reliable truth-preservation through training, obligation, and incentives for the keepers of the traditions. The suggestion is that a reflective historiography should reveal or confirm these mechanisms. Stronger claims about the reliability of oral traditions over tens of thousands of years, like those cited by Henige, are plausibly just extensions of such claims into the long-term trans-generational domain..$^{10}$

\footnotetext{
${ }^{10}$ What makes some theorists optimistic about testimonial reliability over deep time is just their finding it relatively easy to posit the unbroken existence of those knowledge-preserving conditions over very long periods - especially, as it turns out, in aboriginal cultures in Australia, Africa and North America. The assumption that the appropriate social, political, linguistic and psychological conditions would obtain over the necessary time-scales in aboriginal cultures invites particular scepticism. Various possible racial and cultural prejudices lurk here, ranging from the attribution of exotic powers of concentration and purity of purpose to the wise people or shamans of non-literate cultures, to an idealized steady-state conception of aboriginal societies prior to colonial contact. On this latter picture, knowledge is helpfully if mysteriously preserved by static social processes from the indefinite past - at least until European recorders of history arrive on the scene to codify it.
} 
While the conditions sufficient for the preservation of testimonial content over many re-tellings are rarely spelled out in detail, key factors are often taken to include the aims of the tradition-keepers mentioned by Coady. This is made explicit by Jan Vansina, a foundational figure in the modern historiography of oral traditions, and the only historiographer whom Coady cites in support of his endorsement of the reliable preservation of testimony. Vansina is by no means a defender of deep-time testimonial reliability, but he at least provides a somewhat favourable description of some of the truth-conducive mechanisms that might police the reliability of oral traditions in some cultures. A psychological commitment to accuracy on the part of the tradition-keeper is one such mechanism.

The intent of the performance greatly matters. Where, as in the case of tales, innovation on a stable scheme is at a premium, the pulse of change beats faster. Where, to the contrary, the performers intend to stick as closely as possible to the message related to avoid lapses of memory or distortions, the pace of change can almost be stopped (Vansina 1985, p. $41)$.

Now, a thorough treatment would analyze the empirical grounds for thinking that this suggestion from Vansina is over-optimistic - grounds that would implicate a great deal of language pragmatics, and research in cognitive and social psychology, including the empirical study of memory as it underlies testimony. Empirical work on the serial 
reproduction of narratives, beginning with Frederick Bartlett (1920), has been a recurring interest in the social psychology of communication (Allport and Postman 1947; Lyons and Kashima 2006; Kashima, Klein and Clark 2007). Oral historiographers too have increasingly made use of empirical research on memory, in drawing out the connections between memory, testimony, and culture (Thomson 2011; Yow 2005). These empirical details can be bracketed for current purposes, though, since the key point is just that Vansina's posited commitment to sticking to the message is precisely the sort of thing that can lead to significant changes in the message. A different example from Vansina himself helps to illustrate the point.

By the 1950s, the Lulua of Zaire were telling that they originated in a place called Nsagu Lubangu, although that was not what their traditions had been saying hitherto. The old men who knew the older traditions believed that they had been mistaken since the Nsangu Lubangu was taught in a school and schoolmasters must be right (1985, p. 111).

Crucially, the shift in message content described in this case is not a result of the tradition-keepers' intention to corrupt the message, nor even a result of their indifference to message fidelity. It arises from their very intention to safeguard the message. Bringing to bear all the information at their disposal, the tradition-keepers conclude that their tradition has been corrupted at some point, and must be corrected. Why? Because they 
want the message to remain accurate; they wish neither to introduce errors, nor to pass on errors that may have crept in.

The main thing to emphasize for current purposes, though, is that oral traditions are not particularly understood as functionally oriented towards the goal of high fidelity anyhow. ${ }^{11}$ In practical terms, the literature on oral traditions reveals little genuine imperative "to stick as closely as possible to the message related" in the observations of historiographers from the field. At least, the social institutions necessary for oral traditions to be highly reliable content-preserving chains are not reflected in the literature on oral historiography of various cultures. And the functions of oral tradition do not lend themselves to such an implementation in any case. Where oral traditions are found, they are often used as entertainment, education, and political theatre. As Henige observes, "in many societies conveying tradition has performative aspects to it... informants treat the transaction as an opportunity to excel as entertainers, and there is no reason to presume that this has not been the case in any transmissions that preceded the most recent occasion" (2005, p. 85).

Usual themes for even potentially historical traditions include panegyrics and eulogies for rulers or their known ancestors, and "first arrival" stories purporting to

\footnotetext{
${ }^{11}$ Neither are oral historians entirely focused on the accuracy of oral traditions. This point could take us far afield, but can be summarized quite briefly: more historians take oral history and oral traditions seriously than take them seriously for their truth-conducive properties. Some elements of oral historiography overlap significantly with literary theory, ethnography and performance studies. For some theorists, the question of the truth or falsity of oral testimony can be less significant than the performative aspects of oral recollection, or even the personally transformative powers of historical testimony (Pollock 2005, p. 2). So there is at least some reason for caution about over-interpreting the fact that historians, broadly conceived, work with oral testimony, in putatively low-information contexts or not. Again, I will primarily discuss those historians who do focus on the truth or credibility of oral testimony.
} 
recount the migration of a people to their current locale. All of this presupposes real-time responsiveness to audience uptake and a wide range of other contextual factors during the performance of the testimony. Thus it should be unsurprising that the model of highly precise testimonial transmission in oral cultures is more widely assumed than observed, as noted by oral historiographer and Africanist Ruth Finnegan:

It will have been noticed that I have said nothing about "historical poetry" or about "epic." Surely these provide the best and most relevant source for the historian? The truth is that this type of poetry seems surprisingly uncommon in Africa. Certainly there are some exceptions... But in general terms specifically "historical poetry" seems rare as an oral form, and even apparent instances turn out to be basically more like panegyric, the element of narration being subordinate to that of eulogy. True "epic," in spite of widespread assumptions about its being the natural form in many non-literate societies, is hard to find (Finnegan 1970, p. 196).

Even when considering the rare cases having the surface appearance of genuine historical oral traditional, moreover, Finnegan indicates that the expert's standing attitude of assessment is not one of default acceptance after all.

The common picture of formalized historical accounts being passed down from generation to generation by specialists whose duty is to recite and 
transmit them accurately turns out to be not so widely applicable as one might expect...

Even [the] exceptions... involve their own difficulties. Were they really handed down "word for word"? ... Again, the fact that such accounts are often the versions authorized by those currently holding political and/or religious power... means that one must treat them with caution as a historical source. In addition one has to be chary of taking such accounts literalistically... If the traditions of specific "migrations" were taken literally "the history of Gabon would begin with an empty forest only 300 years ago, into which various peoples penetrated abruptly" (Finnegan 1970, p. 197; quoting and translating from H. Deschamps, 1964, p. 175).

Finnegan dryly remarks that one of the common indicators of late additions to older traditions is that the more recent elements are "usually less steeped in supernatural elements than the early portions of such accounts" (p. 197).

These cautionary notes, flagging the rarity and shakiness of oral traditions that purport to preserve accuracy over many transmissions, are not outliers in the wider oral historiography literature. Notwithstanding Coady's emphasis on reliable mechanisms of content preservation in transmission, oral historians who focus on methodology are generally no more than lukewarm in their endorsement of such claims. For example, Coady cites Vansina as the source for his claim that "heavy ritual sanctions against 
mistake" would shape the accuracy of tradition-keepers. And on the cited page, Vansina does remark:

In some cases controls over the faithfulness of the performance were set up and sanctions or rewards were meted out to the performers. The Kuba used only a mitigated form of sanctions. In theory no king could succeed if, during the coronation ceremonies, he could not give a general description of Kuba history, and the candidate for the female office of mbaan, could not be appointed if she could not enumerate the names of her predecessors in office.

However, Vansina immediately continues:

Of course such sanctions were fiction. Who would dare to correct the king on such an occasion, and would the mbaan not be briefed by those who knew the information - if any? No inspectors were set up. Control was exercised by the consensus of the public among the Kuba... [In Rwandan cultures] the only acceptable standard was the remembered performance of the teacher of the performer. If he said it deviated, then the sanction could be applied, and it was death. [I]t is evident that such specialists, all belonging to a single or closely related households, were not ready to point out a failure that would such drastic consequences. No failure is remembered (p. 41). 
Like Finnegan, Vansina recognizes that the appearance of harsh punishment for error can itself be part of the many, many social and political functions for which oral traditions are recruited. Plausibly, the invocation of capital punishment with respect to oral traditions bearing on, say, the history of a people, or the legitimacy of its ruling house, would encourage carefully politic recitations at least as strongly it encouraged truth-preservation. If we consider the personal and socio-political pressures on message fidelity in such contexts of recitation and transmission, it will seem implausible to suppose that these pressures are not actively shaping message contents over practically every timescale. The more we take seriously the specifically social elements of social epistemology, the less surprising such a prospect should seem.

\section{Lessons from oral history}

Taking stock: the historiography of oral tradition does not weigh in favour of (anything very similar to) APT, because oral historians do not, after all, generally demonstrate a methodologically informed default trust of oral testimony in contexts lacking other evidence that would tend to justify the content of such testimony. Rather, influential experts in oral historiography indicate that oral traditions with historicalrepresentational surface features are commonly offered as entertainment or as political endorsement, not as unvarnished truth. And when such traditions are presented as straightforward historical truth, they are taken as reliable only to a degree that fairly demanding background conditions are thought to hold - namely, that the chain of testimonial transmission was conditioned by accuracy-preserving mechanisms, whatever 
those may be. Evidence of such conditions is called for, moreover; otherwise the prospect of shifting messages over time becomes a serious worry. "In the case of prior transmissions of oral tradition, no evidence would remain," writes Henige, "leaving us with nothing but the duty to suspect" (2005, p. 86). This does not seem very much like the view that default acceptance is justified.

But if the historiography of oral tradition does not bolster APT, oral history (and historiography more generally) still holds important lessons for the epistemology of testimony. Here the breadth of academic oral history comes more to the fore, as some of the lessons are predicated on methodologies that overlap with the social sciences, including some approaches to interviewing, while others reflect cultural analysis or interpretive work. I consider four principles bearing on the epistemology of testimony that emerge from my reading of oral history and historiography. It is worth reissuing the caveat that this reading is a partial one, and deliberately focused on issues apt to be of interest to epistemologists, and to issue a second one as well: that presumably none of these ideas is somehow unknown or shocking to an epistemologist. But seeing the methodological roles these lessons sometimes play in oral historiography emphasizes their significance for the social epistemology literature.

5.1. The justified acceptability of testimony is typically a function of the work that goes into constructing the context of communication. 
The point of teaching oral historiography as methodology, especially in the form of practical guidelines or rules, is for researchers to be informed about, and in some cases prepared against, the factors that influence and co-determine testimonial credibility. The emphasis on such factors - preparing questions, preparing devices, choosing a room, settling on a range of protocols, and thinking about how to build an appropriate relationship with the speaker - shows just how much advance preparation they entail, and how dedicated that preparation is to the end of getting some appropriately revealing or contentful result from the speaker in an oral history interview. Some of the recommended preparations themselves presuppose a rich infrastructure investing in expert knowledge and skills. ${ }^{12}$

This is not to say that interview methodologies are universally devoted to nullifying or minimizing every contingency of the speaker, the context, or the interviewer-interviewee relationship. I return to this point in (5.4) below. But the basic point of preparation for a well-conducted testimonial encounter stands in any case. The reductionist-fundamentalist literature in the epistemology of testimony sometimes invites a dichotomy: in the first instance, does an epistemically responsible audience exercise a general entitlement to believe testimony, while merely monitoring background evidence and context for possible defeaters; or do they canvass the evidence upon receipt of testimony to determine whether positive grounds for accepting it are available? The critical emphasis in professional historiography on the advance preparation of testimonial

\footnotetext{
12 This finds a clear expression in Christine Bombaro's advice to researchers: "First, be sure that the person conducting the interview has either a history degree or training in oral history methodology" (2012, p.150).
} 
situations illuminates the prospect that this is not a key question after all. It might not even be a meaningful one in many contexts. When a great deal of knowledge and casebuilding evidence has already gone into shaping a testimonial context, for the specific purpose of enhancing the credibility of testimony received in it, the distinction between monitoring for positive evidence and monitoring for defeaters within the context becomes obscure.

This is not a mere idiosyncrasy of the professional historian's interview context, moreover. I have argued elsewhere that the seeming speed, effortlessness and automaticity of testimonial uptake are quite generally functions of the ways that communicative contexts are actively constructed (ELIDED). The construction is rarely as self-consciously methodical as in the historian's interview, but implicit norms and implicit knowledge perform analogous roles. Indeed, this information is deployed so automatically that its justificatory effects on subsequent uptake are easily overlooked.

One way that I have argued for this is by considering another example from Coady: that of phoning the telephone company to learn the details of one's phone bill. In this situation, Coady argues, one does not even think about assessing the credibility of the anonymous speaker who provides the dollar figure in reply (1992, p.143). But this does not support the relative independence of justified uptake from information about speaker credibility. Rather, I argue, it demonstrates the importance of mobilizing and acting upon one's strong reasons to think that phoning the phone company is a particularly fine way of arranging a conversation with a credible testifier on the topic of one's telephone bill (ELIDED). Testimonial situations are very often engineered or exploited by an audience 
precisely to allow the audience to accept testimony quickly and implicitly when it is received; but masses of evidence bearing on credibility, pitched at many different levels, may already be recruited in that engineering effort. As in the formal interview context, the relevant evidence is neither monitored for potential defeater status as part of a default entitlement to accept testimony, nor canvassed and surveyed for positive force at the point of testimonial uptake. To a significant degree, the relevant evidential considerations are engineered into the testimonial context itself. And this draws out a further lesson.

5.2. The context of the testimonial exchange is not a remote background consideration; it is of immediate significance to uptake and justification.

Henige observes that factors like the socio-economic structure of the testimonial context are essential epistemic considerations for the responsible oral historian; "[t]hese are private, yet social occasions," he writes, that admit of some blunt characterization.

They are also occasions of unequal benefit. Books don't mind being used, but people often do, and the oral historian is treating his informants just as he would treat a book - as a means of furthering his own interests. This is a delicate matter, and is not be resolved on a crass pay-as-you-go basis, which will tempt informants to treat data as commodities, with disastrous results (2005, p.81). 
Whether or not Henige's particular perspective is widely shared, it is clear that other historiographers also emphasize the respects in which structural or social features of the interviewing context itself can influence the quality of testimony obtained in it. Such features include time limitations, resource limitations, and the plenitude of idiosyncratic background conditions that can affect both testifier and audience in ways that are hard to anticipate or forestall. This might include time of day, place of interview, and specifics of the relationship between interviewer and interviewee - how well they happen to hit it off, in short.

On one hand, these observations deepen the point about contextual engineering. In earlier work I proposed the fairly simple example of choosing a person wearing a rail company uniform, rather than a randomly chosen person, to ask which platform my train will leave from. Henige's observations about payment for testimony bring to the fore that someone in a rail company uniform isn't just likelier to know whence a train will depart. She has a complex web of incentives and habits - financial, professional, personal - that condition her answers, and that should condition my views about whether, having chosen to ask her, it is prima facie reasonable to believe what she says. Implicit and explicit sensitivity to this complex web helps to shape our construction of testimonial contexts for epistemic ends.

The further point, however, is how we represent and prioritize this information. Epistemologists sometimes make a point of noting the importance of background knowledge and discursive context; yet to characterize it as background knowledge is to facilitate a focus on a narrow individuation of context, and on the occurrent intentions 
and beliefs of speakers and audiences within that context. Oral historiography suggests that this is a mistake. The factors that bring a speaker to the communicative exchange, and the values and commitments that shape her contributions, are relevant factors - full stop. Whatever cognitive distinction might be limned between background and nonbackground information in this domain, there is no reason to think it should track an epistemological distinction among the considerations determining the justificatory status of beliefs formed through testimony.

\subsection{Properties of the audience are crucial to assessments of the justification of beliefs derived from testimony.}

In the analytic epistemology literature, it is fairly common to bracket or simply not discuss the role of the audience's interpretive and evaluative heuristics in co-determining justified uptake, and to focus on properties of the speaker, the proposition asserted, and the available contextual evidence. By contrast, historical methodologists typically note a much wider range of considerations that oral historians must factor into the assessment of (and preparation to receive) testimony gained through interviews.

Some of these considerations apply also to the speakers themselves - for example, prospects for lapses of memory, unfairness through vindictiveness, a distorting superficiality, oversimplification, self-aggrandizement, reticence, limitations of perspective, and the contamination of memory through factors like hindsight and postevent information from other sources (Seldon and Pappworth 1983, pp. 17-35). But 
historiographers may also cite limitations and dispositions of the interviewer as factors that influence uptake during the interviewing process. As oral historiographer Paul Thomas observes, "[i]t is certainly ... clear that interviewers carry into the interview both their own expectations and a social manner which affect their findings" (2000, pp. 138-9).

Among these expectations are audience assumptions about the speaker's representativeness, presuppositions or biases in questioning, attitudes towards interviewees themselves (perhaps deference, perhaps others), and degrees of reliance on oral sources relative to written sources. These assumptions condition the uptake of testimony on the audience's part, and thus are apt to influence the justification of beliefs or judgements arising from the testimony. Just as the historian must consider whether such factors are, in the event, affecting the speaker in a way that bears on the justifiability of accepting her testimony, so too are the effects of the interviewer's expectations and dispositions a key question for the purpose of epistemically responsible uptake. Indeed, the overall distribution of relevant agentive considerations described by Seldon and Pappworth is quite balanced between those applying to speakers and those applying to audiences. This sort of balanced taxonomy of factors influencing the credibility of testimony suggests an oversimplification or naiveté in any epistemological treatment that treats the speaker, or the speaker-plus-context, as the main focus. This observation applies both to anti-reductionist views on which the speaker is monitored for the purpose of defeater-detection, and reductionist views on which the justification for testimonial belief is depicted as an amalgam of the hearer's evidence regarding a speaker's competence, sincerity, or credibility. 
Lackey's dualist view of testimony (2008 pp. 176-194), which explicitly emphasizes properties of speaker and audience, may be the extant position that most clearly sidesteps this concern. In particular, Lackey proposes that warranted belief on the basis of testimony requires (among other things) both that the speaker be "reliable or otherwise truth-conducive" and that the audience be "a reliable or properly functioning recipient of testimony" (p. 177). What is it for an audience to be "properly functioning"? Here too the epistemology is enriched by the historiography. A simple and common answer is that the audience should have no undefeated defeaters bearing on the testimony; Lackey supplements this with the requirement that the audience moreover have positive evidence for accepting the testimony. By contrast, the factors of which the interviewer should be (self-)aware and controlling for, under oral historiographical methodology, are far more fine-grained and epistemically diagnostic. They go to the questions of whether the audience or interviewer is prepared to interact with the speaker in ways that will elicit truth-conducive testimony, and whether that testimony will be taken up in truth-conducive ways. This implicates audience dispositions to foster trust, to attend carefully to utterances, to recall testimony reliably, to debias uptake in a manner that holds off the influences of various common biases, and generally to interpret testimony with the appropriate balance between charity, in constructing a plausible assertion, and fidelity, in representing the communicative aims of the speaker accurately. An epistemological emphasis on these factors will be crucial for understanding testimonial justification - and failures of justification as well. 


\subsection{Testimony has more than one truth-conducive proper function.}

Alessandro Portelli's approach to oral history is a particularly good example of the idea that testimony acts to our epistemic advantage in ways that go well beyond the linguistic recovery of asserted propositions. In his deeply influential The Death of Luigi Trastulli, Portelli reports interviewing members of the Italian socialist labour movement regarding the (independently confirmable) 1949 death of a young protester in leftist anti-NATO rallies of the time (1991). Portelli discovers that many testifiers blended some events in memory, eliding other events altogether, and mistakenly placing themselves at the centre of many events. But this discovery leads Portelli, not to a scepticism about oral history, but to a more complicated understanding of the connections between the truth-value of testimony and the historian's ability to learn from it.

Some of these infelicities in testimony are described by Portelli in ways that might suggest that the truth-value of the testimony itself is of little significance to historical inquiry as he understands it. For instance, Portelli characterizes one internally consistent but false piece of testimony about Trastulli's death in the following way: 'Matteucci's story is a faithful description of what happened in the October 1953; the only thing “wrong” with it is that this wasn't when Trastulli was killed' (1991, pp. 13-14). This appearance is perhaps heightened by Portelli's widely-cited description of oral history's virtues, with his use of more scare-quotes suggesting ambivalence about the very concepts of accuracy or error in the broader oral history project. 
Oral sources are credible but with a different credibility. The importance of oral testimony may lie not in its adherence to fact, but rather in its departure from it, as imagination, symbolism, and desire emerge. Therefore, there are no "false" oral sources. Once we have checked their factual credibility with all the established criteria of philological criticism and factual verification which are required by all types of sources anyway, the diversity of oral history consists in the fact that "wrong" statements are still psychologically "true," and that this truth may be equally as important as factually reliable accounts (1991, p. 51).

Even allowing for the allusion to factual credibility and the importance of verification, it may seem a fairly dramatic non-sequitur to conclude that there is no false (or "false") oral testimony from the fact that there is false oral testimony and that it can be important.

The tensions between these ways of speaking are real, but it would be a mistake to characterize Portelli as not much caring about the accuracy of testimony, nor about the determination of historical truth through inquiry more generally. In fact Portelli's approach is predicated on the thought that, even when the historical interest of testimony transcends its immediate reliability, we may be interested in that testimony precisely because we are interested in truth. There are two clear respects in which this is so. First, methodologically, the historian on Portelli's model tracks oral testimony's known departures from the truth. And second, the payoff for attending to testimonial inaccuracy 
in this way is an epistemically improved understanding of social history and collective memory.

It is worth emphasizing this twofold point, because to carve the terrain of oral historiography in a way that sharply distinguishes Portelli's approach from one that emphasizes truth, testimonial reliability, or accuracy is to risk shortchanging the former's breadth of appeal. Alistair Thomson, for example, characterizes the focus on reliability, and methodological concerns about bias or message-drift in oral testimony, as tracing back to an older, politically right-wing "positivistic" view. Thomson contrasts this with an approach, associated with Portelli, that embraces the subjective character of oral sources and methods (2011, pp. 79-80). Yet the quoted passage from Portelli depicts the independent verification of testimony as uncontroversial - as essential methodology in all contexts. This much seems to be a standard assumption in a considerable range of oral historiography training sources; that is, "[w]here accuracy is an issue, oral evidence should always be cross-checked with other sources" (Jordanova 2000, p. 53).

The emphasis on truth-conducivity lending itself to an analytic epistemology of testimony requires no more than that. Whatever methodological scruples and metaphysical commitments are encompassed by Portelli's allusion to the "factual verification... required by all types of sources anyway," and Thomson's reference to “1980s positivist notions of researcher objectivity” (2011, p. 81), key elements of Portelli's insights ought to be ideologically accessible both to the most truth-focused analytic epistemologist and to oral historiographers inclined to celebrate the subjective aspects of their field and practices. For example, social historian Tamara Harevan cites 
Vansina's claim that "testimony is no more than a mirage of the reality it describes... either consciously or unconsciously, a distorted account of what has really happened" (Vansina 1965, p.76). Though it may be an option to reject as positivistic the very notion of realism underlying this claim, Harevan elects instead to situate the subjective virtues of oral testimony within the scope of that realism. Oral history is a subjective process in the way Vansina suggests, according to Harevan, but its reflection of personalities, values, and circumstances are "precisely its great value, rather than its limitation" (Harevan 1984, pp. 254-5). This seems an approach comparable to Portelli's: the strict truth of a piece of testimony might fail to be the crucial consideration, not necessarily because truth is a suspect notion tout court, but because there are many other truths illuminated by an understanding of how even false testimony comes to have its content, in its context, in the mouth of its particularly situated speaker.

In the Luigi Trastulli case, Portelli's insight is that there is a pattern among testifiers of transposing Trastulli's death from anti-NATO protests of 1949 into antilayoff protests of the early 1950s. By understanding that this is a mistake, and by understanding some details of the intervening years - for example, that the Italian Left had become pro-NATO but remained staunchly unionist in the interim - Portelli is able to infer something about the social history and collective memory-shaping processes of intervening decades. But this is (ideally, at least) using truths to infer truths; the known falsity of the testimony is a crucial premise in historical inquiry of this sort. That "narrators do not seem to concern themselves excessively about chronological accuracy," as Portelli notes, is not only a fact that illuminates history through the particularities of 
the narrators' anachronisms. It moreover requires the oral historian herself to attend closely to the details of chronological accuracy, in order to detect the "uchronic" or idealized reordering of events as a narrator describes them. ${ }^{13}$ The upshot is not a positive distrust of memory and its connections to testimony in general, but rather a deeply evidentially conditioned reliance on it, and a willingness to use it to epistemic advantage even when the memories and associated testimony contain false elements.

Naturally the literature on the epistemology of testimony envisions the prospect of drawing inferences from information gleaned obliquely through testimony. But Portelli's investigation of the articulations linking testimony with epistemic improvement is richer than the thin or schematic examples typically provided in the philosophical literature. And it is not merely richer for being a real-world example - in Portelli's methodology, this is one of oral testimony's proper intellectual functions in a historical inquiry. A natural reading of Portelli's scare-quotes is to see them as conveying, not a rejection of the very concepts of truth and error as applied to testimony, but a straightforward openness to mining partly false testimony for information that generates accurate historical insight. This is one of the things that testimony is for, to Portelli's historian.

What would it be to import this approach into epistemological theorizing about testimony? Where Portelli extracts "imagination, symbolism and desire" on the grander socio-political scale from testimony, the epistemologist may recognize them also on the

\footnotetext{
${ }^{13}$ The articulation of these connections between the contents of a tradition and the broader truths about a culture or polity that may be gleaned from the tradition is one of the important contrasts between Portelli's approach and that of anthropologist Peter Nabokov, whose selection of texts (many transcribed from the oral) for a collection on Native American testimonies is premised on the idea that more recent reports, those more isolated from the events described, are simply more accurate by dint of being less fraught with "pain and confusion" (1999, p. xxii).
} 
micro-social scale. For example, mythologizing as personal history is arguably as much a rule as an exception, depending on the topics and time scales in question. Consider, for example, the rather popular trope of the self-made person, so widely offered as personal history by people of obvious antecedent privilege. ${ }^{14}$ Following Portelli's approach, the inferable errors and exaggerations of such testimony provide critical leverage for an understanding of speakers' past and present circumstances, their relations to socioeconomic institutions, and their dispositions to identify with other people of comparable industry and intellect but fewer initial advantages. Taking this sort of epistemic improvement seriously will colour one's interpretation of the oft-cited ubiquity of testimonially-dependent knowledge and justification. Arguably, the breadth of our broadly testimonial knowledge and the depth of its justification are artifacts of such indirect but fecund connections between testimony and warranted belief.

Competent listeners avail themselves of these understandings where possible; but the contemporary literature in the epistemology of testimony is prone to assimilating such testimony-generating true beliefs to deviant cases - like coming to believe that someone is coughing by hearing them say, unintelligibly, while coughing, "I am coughing." For many influential writers, what lumps the coughing case together with the self-made person case is that the resulting belief is not based on testimony, in the technical sense of basing (ELIDED). If we did look to oral history and oral historiographers for guidance on the epistemology of testimony, one lesson to draw might well be that this disaggregation of beliefs arising from testimony - the distinction between those strictly based on

\footnotetext{
${ }^{14}$ An example suggested in Green \& Troup 1999, p. 235.
} 
testimony and those of little inherent philosophical interest - was too sharp and too hasty all along. But the idea of a continuum of evidentially supported or corroborated testimony-generated beliefs in turn looks more like a manifestation of testimonial reductionism than of testimonial fundamentalism. These cases would then just be variants of the complicated ways in which beliefs stemming from testimony can be justified, rather than being epistemically distinct phenomena.

\section{Conclusion}

The degree and kind of interest and deference that oral historians pay to verbal testimony in low-information contexts does not count in support of APT, all in all. In his 1930 analysis of Icelandic family sagas, Knut Liestøl wrote that "we can neither say of oral tradition that it is essentially reliable or unreliable, nor that it is essentially shortlived or long-lived. Everything depends on the conditions in which it lives" (p. 234). Very little in the oral historiography literature since Liestøl issued this remark has emerged to support the more general default trust of testimony predicted by the hypothesis that oral historiographers have adopted APT. Experts on oral history commonly take the intellectual value of such testimony to consist in its social, political, cultural, personal, and entertainment functions, and not only - or not even - in its accurate depiction of past events. And even when descriptive accuracy is the emphasis, many historians of oral tradition seem not to trust oral tradition to the extent, or in the manner, predicted by APT; the importance of gathering supporting evidence and crosschecking claims for accuracy is, if not a universal emphasis, at least a major one. 
Oral historiography holds different and arguably broader lessons for social epistemology. It suggests that the justified or warranted uptake of testimony critically involves a wider range of social and contextual factors than the philosophical literature might otherwise reflect. It confirms the epistemological significance of actively constructing testimonial contexts, in ways that extend quite naturally to common conversational activity. The weighing of diverse kinds of evidence, the social construction of interview contexts, and the varieties of communicative aims are often invisible in the simplified examples of discourse that have characterized the philosophical literature on testimony. That historiography makes these complications central to professional assessments of the reliability of oral testimony should be a matter of import to social epistemology. 


\section{References}

\section{(SELF-REFERENCES REMOVED FOR ANONYMOUS REVIEW)}

Allen, B \& Montell, W. 1981. From Memory to History. Nashville: The American Association for State and Local History.

Allport, G. and Postman, L. 1947. The Psychology of Rumor. New York: Henry Holt and Co.

Almassi, B. 2009a. Conflicting expert testimony and the search for gravitational waves. Philosophy of Science 76.5: 570-584.

Almassi, B. 2009b. Trust in expert testimony: Eddington's 1919 eclipse expedition and the British response to general relativity. Studies in the History and Philosophy of Science Part B 40.1: 57-67.

Audi, R. 2006. Testimony, credulity, and veracity. In J. Lackey and E. Sosa (eds.) The Epistemology of Testimony. Oxford: Oxford University Press. 25-49.

Augustine, S.J. 2008. Oral histories and oral traditions. In Aboriginal Oral Traditions: Theory, Practice, Ethics. R. Hulan and R. Eigenbrod (eds.) Halifax: Fernwood Publishing, pp. 2-3.

Bartlett, F.C. 1920. Some experiments on the reproduction of folk stories. Folk-Lore 31: $30-47$.

Bombaro, C. 2012. Finding History. Toronto: Rowman and Littlefield.

Coady, C.A.J. 1992. Testimony: A Philosophical Study. Oxford: OUP. 
Deschamps, H. 1964. Traditions orales au Gabon. In The Historian in Tropical Africa, ed. J. Vansina . London: Oxford University Press.

Deur, D. 2002. A most sacred place: The significance of Crater Lake among the Indians of Southern Oregon. Oregon Historical Quarterly 103.1: 18-49

Dunaway, D. \& Baum, W. Introductory remarks to 'Preface to The Saga of Coe Ridge'. In D. Dunaway \& W. Baum (eds.) Oral History: An Interdisciplinary Anthology. Nashville: American Association for Local and State History. 165.

Finnegan, R. 1970. A note on oral tradition and historical evidence. History and Theory 9.2: 195-201.

Freedman, K. 2014. Testimony and epistemic risk: The Dependence Account. Social Epistemology: A Journal of Knowledge, Culture and Policy. DOI: $10.1080 / 02691728.2014 .884183$

Gilovich, T. 1991. How We Know What Isn't So. New York: The Free Press. Graham, P. 2006. Liberal fundamentalism and its rivals. In J. Lackey and E. Sosa (eds.) The Epistemology of Testimony. Oxford: Oxford University Press.

Green, A. \& Troup, K. 1999. The Houses of History. Manchester: Manchester University Press.

Haraven. T. 1984. The search for generational memory. In D. Dunaway \& W. Baum (eds.) Oral History: An Interdisciplinary Anthology. Nashville: American Association for Local and State History. 248-63.

Henige, D. 2005. Historical Evidence and Argument. Madison: University of Wisconsin Press. 
Jordanova, L. 2000. History in Practice. London: Arnold.

Kashima, Y., Klein, O. \& Clark, A. 2007. Grounding: Sharing information in social interaction. In K. Fiedler (ed.). Social Psychology and Communication. Philadelphia, PA: Psychology Press.

Lackey, J. 2008. Learning from Words. Oxford: Oxford University Press.

Liestøl, K. 1930. The Origin of the Icelandic Family Saga. A. G. Jayne (trans.) Cambridge MA: Harvard University Press.

Locke, J. 1689. An Essay Concerning Human Understanding. Online digital version ILT Digital Classics 1995. http://www.ilt.columbia.edu/publications/locke_understanding.html

Lyons, A. \& Kashima, Y. 2006. Maintaining stereotypes in communication: Investigating memory biases and coherence-seeking in storytelling. Asian Journal of Social Psychology 9:59-71.

Miller, B. forthcoming. Scientific consensus and expert testimony in courts: Lessons from the Bendectin litigation. Foundations of Science.

Nabokov, P. 1999. Native American Testimony, Revised Edition. New York: Penguin.

Pollock, D. 2005. Remembering. In Remembering: Oral History Performance. D. Pollock (ed.) New York: Palgrave Macmillan. 1-18.

Portelli. A. 1991. The Death of Luigi Trastulli and Other Stories: Forms and Meaning in Oral History. Albany, NY: SUNY Press.

Pritchard, D. 2004. The epistemology of testimony. Philosophical Issues 14: 326-48. 
Seldon, A. \& Pappworth, J. 1983. By Word of Mouth: Elite Oral History. London: Methuen.

Sitton, T., Mehaffy, G. \& Davis O. 1983. Oral History: A Guide for Teachers (and Others). Austin: University of Texas Press.

Thomas, P. 2000. The Voice of the Past: Oral History (3rd ed.) Oxford: Oxford University Press.

Thomson, A. 2011. Memory and remembering in oral history. In The Oxford Handbook of Oral History. D. Ritchie (ed.) Oxford: Oxford University Press. 77-95.

Walton, D. 2008. Witness Testimony Evidence: Argumentation, Artificial Intelligence, and Law. Cambridge: Cambridge University Press

Vansina, J. 1985. Oral Tradition as History. Madison: University of Wisconsin Press.

Vansina, J. 1965. Oral Tradition: A Study in Historical Methodology. Chicago: Aldine Publishing.

Yow, V. 2005. Recording Oral History: A Guide for the Humanities and Social Sciences, $2^{\text {nd }}$ ed. Walnut Creek, CA: AltaMira Press. 


\section{Acknowledgements}

For helpful input and feedback on this work, the author would like especially to thank Shannon Dea and Douglas Peers, as well as Wesley Buckwalter, Eric Hochstein, Carla Fehr, Doreen Fraser, Steven High, and Rachel McKinnon. This work was supported in part by the Faculty of Arts, University of Waterloo, and by Social Sciences and Research Council of Canada Grant 410-2011-1737. 